\title{
Knowledge and awareness about cervical Cancer and its Prevention among Women Attending at Out patient Department of Dhaka Medical College Hospital
}

\author{
Lipi L B ${ }^{1}$, Kutubi $A^{2}$, Rahman $M_{M^{3}}$, Shaha $N^{4}$, Haque ${ }^{5}$, Ara I ${ }^{6}$
}

Conflict of Interest: None

Received: $10-12-2017$

Accepted: 06-03-2018

www.banglajol.info/index.php/JSSMC

Key Words:

Ca cervix- Cervical cancer, VIAvisual inspection with acetic acid, HPV- human papilloma virus

\begin{abstract}
:
The purpose of this study was to assess the knowledge and awareness regarding cervical cancer and its prevention among women attending at out patient department of Dhaka Medical College Hospital. A qualitative study was undertaken using face to face in depth interviews

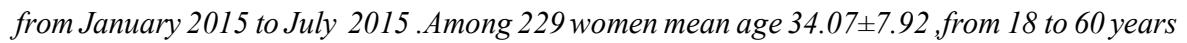
were observed. Awareness and knowledge about cervical cancer was very poor which was about $25.3 \%$. Knowledge was high among women coming from high socioeconomic condition which was $31.5 \%(p=0.03)$. Participants who were highly educated had more knowledge about $83.3 \%(<0.001)$. Most of the participants about $72.22 \%$ got the information from doctors and health service providers. The findings highlights the importance of awareness creation about cervical cancer and its risk factors, screening through utilization of the services of media like television, newspaper and radio which have massive impact in improving the knowledge.
\end{abstract}

[J Shaheed Suhrawardy Med Coll 2018; 10(1): 36-41] DOI: http://dx.doi.org/10.3329/jssmc.v10i1.38902

\section{Introduction}

Cervical cancer is the second most common cancer among women in the developing world and major cause of morbidity and mortality in resource-poor settings where access to cervical cancer screening and vaccination is limited. ${ }^{1}$ Globally- 527624 new cases - half the global burden is in Asia, one quarter in Southern Asia ${ }^{2}$. In Bangladesh yearly burden of cervical cancer is about 17686 and around 10364 women die from cervical cancer each year ${ }^{3}$. Hospital based data revealed that cervical cancer constitutes $22-29 \%$ of female cancer in Bangladesh ${ }^{4}$. Over $80 \%$ of cervical cancers in sub-Saharan Africa are detected

1. Dr. Lutfa Begum Lipi, Assistant Professor, Department of Obst \& Gynae, Dhaka Medical College Hospital, Dhaka

2. Dr.Afroza Kutubi, , Associate Professir, Department of Obst \& Gynae, Dhaka Medical College Hospital, Dhaka

3. Dr. Mohammed Mizanur Rahman, Associate Professor, Urology, National Institute Of Kidney Diseases And Urology.

4. Dr. Nebedita Shaha, Assistant Registrar, Department of Obst \& Gynae, Dhaka Medical College Hospital, Dhaka

5. Prof Nazma Haque, Professor, Department of Obst \& Gynae, Dhaka Medical College Hospital, Dhaka

6. Prof. Iffat Ara, Professor, Department of Obst \& Gynae, Popular Medical College, Dhaka

Correspondence to: Dr. Lutfa Begum Lipi, Assistant Professor, Department of Obst \& Gynae, Dhaka Medical College Hospital, Ph-+01712601004, lutfa.ssmc@gmail.com in late stages, predominantly due to lack of information about the disease and lack of screening services. ${ }^{1}$ Women with cervical cancer in this region are not identified until they are at an advanced stage of disease.

Bangladesh is a developing country with limited resources. The Government of Bangladesh (GOB) has developing a cervical cancer screening program through Visual Inspection of Cervix with Acetic Acid (VIA). GOB has a plan to make it a nation-wide program. VIA is performed at upazilla health complexes, Maternal and Child Welfare Centres (MCWCs), District Hospitals (DHs), Medical College Hospitals (MCHs) and Bangabandhu Sheikh Mujib Medical University (BSMMU) by trained Family Welfare Visitors (FWVs), Senior Staff Nurses (SSNs) and Doctors. ${ }^{5}$

The trained persons use VIA technique to detect the precancer or early stages of cervical cancer among women 30 years and above visiting the mentioned centers. VIA positive women are referred to BSMMU and various government $\mathrm{MCH}$ for colposcopic evaluation and necessary management.This service is technically and financially supported by GOB, BSMMU and UNFPA.

However, only three lac women have received screening services during the last five years. During evaluation of 
the 'Cervical Cancer Screening Program of Bangladesh' low coverage of the target population was observed ${ }^{6}$. Lack of awareness about cervical cancer and its prevention, low availability of services may be underlying factors for this low intake of services. In fact, several studies have mentioned that the uptake of screening in developing countries is poor.$^{7}$ Lack of awareness of cervical cancer has been identified as one of the factors contributing to the high prevalence of this condition in the developing world compared to the developed one. ${ }^{8}$ Cervical cancer prevention programmes have failed to meet their objectives in developing countries due to financial, social and logistical problems ${ }^{9}$.

To prevent new cancers from starting, scientists look at risk factors and protective factors. Risk factors for cervical cancer are the human papillomavirus infection (HPV)( a common sexually transmitted virus), genital infection, having sex at an early age, multiple sexual partners, Smoking or using tobacco, using birth control pills for a long time, weakened immune system- such as those who have human immunodeficiency virus (HIV) infection, been exposed to diethylstilbestrol (DES) before birth. The risk factors of the disease can be avoidable if one can possess proper knowledge regarding the disease process and progression. ${ }^{10,11}$

Out of all the female genital tract cancers, it is the only preventable cancer if detected at its early stages. Population-based screening with Pap smear is an important secondary preventive measure for cervical cancer that leads to a high-cure rate among cervical cancer patient. VIA is a established method of screening in low resource countries perfomed only using 3--5\% acetic acid in cervix for one minute. VIA positive and abnormal paps smear recommend colposcopy. For detection of causative agent HPV DNA test plays a very important role. ${ }^{12,13}$

At present we have sufficient knowledge to prevent at least one third of cancers depending on the availability of resources, early detection and effective treatment of predisposing factors. Further third could be cured with modern amenities. Also there is cancer control strategy in Bangladesh. Government has taken programmatic steps towards developing the cervical cancer screening program. Nationwide Pilot program of preventing cervical cancer among 50 adolescent girls of 9-13 years of age is started in 2007.

Cervical cancer is one of the important enlisted non communicable disease of WHO. ${ }^{14}$ So to decrease the country and global burden of the disease from the society the community perception regarding the screening, disease process, progression and treatment have to be assessed first. So this study was undertaken to assess the knowledge and perception of cervical cancer, its risk factors, prevention and source of knowledge among women attending out patient department in Dhaka Medical College Hospital.

\section{Methods and materials}

At Out Patient Department of Dhaka Medical College Hospital 229 women of reproductive age who were physically and mentally sound to give interview were enrolled in this study. Period of study was from July, 2015 to December,2015 for six months. A qualitative study was undertaken using face to face in depth interviews by a preset questionnaire. The questionnaire includesthe participants' demographic characteristics such as age, highest level of education attained, marital status, number of children, previous health seeking behaviours, use and methods of contraception, questions on awareness and sources of information about cervical cancer, its risk factors cervical cancer prevention measuresand screening methods. A consent form was prepared. Questionnaire was filled with informed written consent. Expert opinions was taken from specialists of the Department of Gynae\& Obstetrics, pathology, virology department of $\mathrm{DMCH}$, Dhaka. All data were checked and edited after collection. Frequency distribution and normal distribution of all continuous variables were calculated and chart was prepared by spreadsheet of Windows 7. Data were entered into computer and analyzed with the help of SPSS windows version 17 . ' $P$ ' values $<0.05$ was considered as statistically significant.

\section{Result :}

Age of the respondents was from 18 to 60 years. Majority in between $30-39$ years. Mean age of the respondents were $34.07 \pm 7.92$.All were married and about sixty percent respondents had got marriage between 15 to 18 years. Mean age at marriage of the respondents is $16.12 \pm 2.83$. About $52.4 \%$ women used oral contraceptive pill. Women aged more than 40 years have more knowledge which is about $31.4 \%$. Majority were educated upto primary level $(51.5 \%)$.Educated respondents who completed above secondary education about $83.3 \%$ had more knowledge .\% participants believe oral pill is a risk factor. 
Table I

\begin{tabular}{|c|c|c|}
\hline \multicolumn{3}{|c|}{ Patients clinical characteristics } \\
\hline Characteristics & Frequency & Percent \\
\hline \multicolumn{3}{|l|}{ Age in years } \\
\hline Below 30 years & 65 & 28.4 \\
\hline $30-39$ & 94 & 41.0 \\
\hline Above 40 years & 70 & 30.6 \\
\hline Mean \pm SD & $34.07 \pm 7.92$ & \\
\hline \multicolumn{3}{|l|}{ Para } \\
\hline 1 & 5 & 10.9 \\
\hline 2 & 25 & 54.3 \\
\hline 3 & 9 & 19.6 \\
\hline 4 & 7 & 15.2 \\
\hline Mean \pm SD & $2.36 \pm 0.85$ & \\
\hline \multicolumn{3}{|l|}{ Age of marriage } \\
\hline$<13$ years & 65 & 28.8 \\
\hline $14-18$ years & 94 & 55.9 \\
\hline$>18$ years & 70 & 15.3 \\
\hline Mean \pm SD & $16.12 \pm 2.83$ & \\
\hline \multicolumn{3}{|l|}{ Education } \\
\hline Illiterate & 23 & 10 \\
\hline primary & 118 & 51.5 \\
\hline secondary & 76 & 33.2 \\
\hline Above secondary & 1 & 5.2 \\
\hline \multicolumn{3}{|c|}{ Monthly income (Taka) } \\
\hline$<10,000$ & 156 & 68.12 \\
\hline$>10,000$ & 73 & 31.88 \\
\hline \multicolumn{3}{|c|}{ Method of contraception } \\
\hline pill & 120 & 52.4 \\
\hline condom & 41 & 17.9 \\
\hline injectable & 29 & 12.66 \\
\hline $\mathrm{Cu} \mathrm{T}$ & 16 & 6.99 \\
\hline NO method & 23 & 10.05 \\
\hline
\end{tabular}

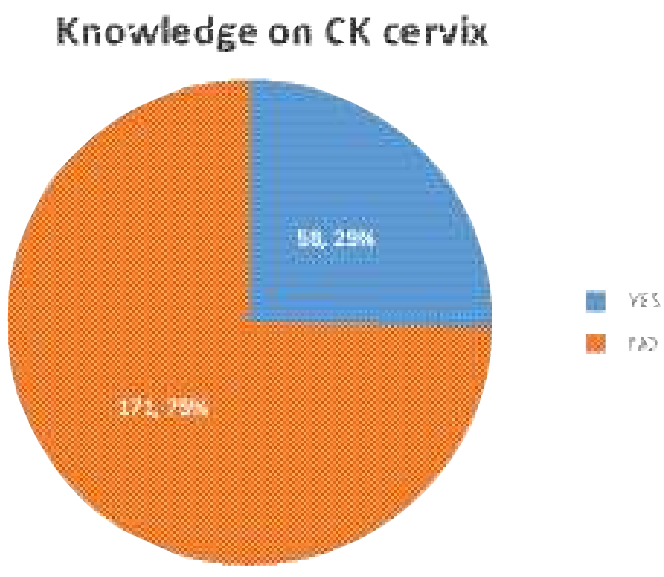

Fig.-1: Knowledge on ca cervix
Table II

\begin{tabular}{|c|c|c|c|c|}
\hline \multicolumn{5}{|c|}{$\begin{array}{l}\text { Relationship between age of the respondents and } \\
\text { knowledge on cervical cancer }\end{array}$} \\
\hline \multirow[t]{2}{*}{ Age } & \multicolumn{2}{|c|}{ Knowledge on cervical cancer } & \multirow[t]{2}{*}{$\chi^{2}$} & \multirow[t]{2}{*}{$P$} \\
\hline & Yes & No & & \\
\hline \multirow{2}{*}{$\begin{array}{l}\text { Below } 30 \text { years } \\
30-39\end{array}$} & $1726.2 \%$ & $4873.8 \%$ & 2.701 & 0.259 \\
\hline & $1920.2 \%$ & $7579.8 \%$ & & \\
\hline Above 40 & $2231.4 \%$ & $4868.6 \%$ & & \\
\hline Total & 58 & 171 & & \\
\hline
\end{tabular}

\section{Table III}

Relationship between education \& income of the respondents with knowledge of cervical cancer

Education Knowledge on cervical cancer $\div^{2} \quad \mathrm{P}$

\begin{tabular}{|c|c|c|c|c|}
\hline & Yes & No & & \\
\hline Illiterate & $28.7 \%$ & $2191.3 \%$ & 36.372 & $<0.001$ \\
\hline Up to primary & $1815.3 \%$ & $10084.7 \%$ & & \\
\hline Above primary & $2836.8 \%$ & $4863.2 \%$ & & \\
\hline Above secondary & $1083.3 \%$ & $216.7 \%$ & & \\
\hline Total & 58 & 171 & & \\
\hline \multicolumn{5}{|c|}{ Monthly income(Taka) } \\
\hline$<10,000$ & 2918.6 & 12781.4 & 4.728 & 0.03 \\
\hline$>10,000$ & 2331.5 & 5068.5 & & \\
\hline
\end{tabular}

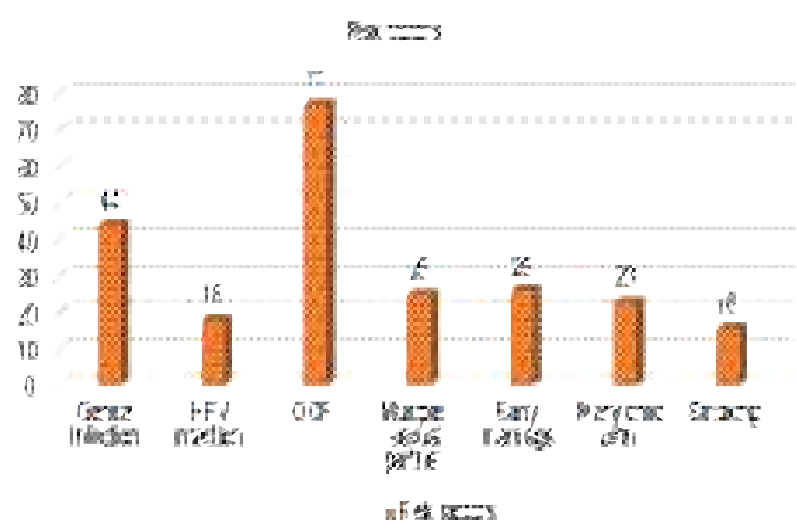

Fig.-2: Knowledge on various risk factors

They heard of cancer from various sources such asUthanboithok (12.07\%), electronic \&Printmedia (6.9\%), Miking of VIA camp (8.62\%), Doctors and other hospital service providers $(70.69 \%)$, and others $(1.72 \%)$. 
TableIV

\begin{tabular}{llcc}
\multicolumn{2}{c}{ Distribution of different source of information $(n=229)$} \\
Serial no & Source of information & Number & Percentage \\
\hline 1 & Uthanboithok & 7 & 12.07 \\
2 & electronic \& Print media & 4 & 6.9 \\
3 & Miking for VIA camp & 5 & 8.62 \\
4 & Doctors and health service provider & 41 & 70.69 \\
5 & others & 1 & 1.72 \\
\hline
\end{tabular}

Table-V

\begin{tabular}{llcc}
\multicolumn{4}{c}{ Cervical cancer screening perceptions and women's attitude attending DMC GOPD $(n=229)$} \\
Variables & Responses & $\mathrm{n}$ & $\%$ \\
\hline Perceives self at risk & No & 92 & 40.17 \\
& Yes & 137 & 59.83 \\
Ever been screenedfor cervical cancer & No & 201 & 87.77 \\
& Yes & 28 & 12.23 \\
Reasons for notscreening & Did not have informationHave no complaints & 15427 & 67.2411 .79 \\
& Told procedure painful & 18 & 7.86 \\
& Too embarrassed to expose private parts & 30 & 13.11 \\
Intention to screenin the future & No & 23 & 10.04 \\
& Yes & 206 & 89.96 \\
Reasons for unwillingness toscreen for & Told had no cancer & 4 & 17.39 \\
cervical cancer in the future & Had a hysterectomy performed & 5 & $21.74 \%$ \\
& Felt the procedure was too embarrassing & 14 & $60.87 \%$ \\
\hline
\end{tabular}

\section{Discussion:}

Among 229 only $25.3 \%$ of our respondents had some knowledge about cervical cancer and itsrisk factors.A recent qualitative study reported a low level of knowledge on HPV and cervical cancer among children, parents, teachers, community leaders and even health service providers of four developing countries (India, Peru, Uganda and Vietnam) ${ }^{15}$. Very similar results, i.e. lack of proper knowledge regarding cervical cancer, were found in several studies conducted in other countries in the world. $^{16-20}$

In Bangladesh, risk factors for cervical cancer are related to early marriage, early onset of sexual activities, multiparity, STD, s and low socioeconomic condition. Lack of knowledge about the risk factors is also an important determinant behind the increasing incidence of these cancers. Among the participants only 18(7.86\%) mentioned
HPV infection as a risk factor but $77(33.62 \%)$ believe use of oral contraceptive pill as riskfactor. This is not consistent with findings from a similar study conducted in northern Uganda. ${ }^{21}$ The high knowledge and awareness from that study indicates that women may be in position to recognize cervical cancer basing on its symptoms and seek medical attention. Also, when women are aware of the causes and risk factors of cervical cancer and perceive themselves to be at risk, they are more likely to take up measures to prevent the acquisition of human papilloma virus .According to the US National cancer Institute's 2005 Health Information National Trends Survey, only 40\% of American women surveyed had heard of human papilloma virus infection \& $20 \%$ had heard of its linkage to cervical cancer. ${ }^{22}$

Women's perception of being at risk of cervical cancer was earlier found to be associated with their intention to 
go for screening services. ${ }^{23}$ In this study $59.83 \%$ perceive self at risk. Reasons not to do screening were had no symptoms $11.79 \%$ and had no information $67.24 \%$. But $89,96 \%$ women want to screen themselves in future. Better education about $83.3 \%$ (p value $<0.0001)$ and high income group about $31.5 \%$ ( $p$ value -0.03 )were found to have significant impact on the awareness which is consistent with findings in studies done in Wufeng County, China .${ }^{24,25}$ So they had more willingness for screening. In a study by Jia conducted in China, women who had lower incomes had higher willingness to screen compared to their other counterparts ${ }^{26}$ while a Botswanan study found that previous cervical cancer screenings was high among women of higher incomes. ${ }^{27}$ Most of the repondents about $70.69 \%$ got the information from doctors and health service providers . In a study findings revealed that audiovisual materials such as cable line advertisement (25.5\%) and mike announcement $(21.4 \%)$ were more effective for increasing awareness than the print media (12.9\%). Television was mentioned as the best method of awareness creation for preventing cervical cancer by $37.4 \%$ of women attending VIA Camp. ${ }^{28}$

\section{Conclusion}

Cervical cancer is a type of cancer which can be identified in its precancerous stage and it takes a long time to be malignant. If cancer cervix is treated in its precancerous form successfully the lesions do not develop into invasive cancer.

Our study population shows poor knowledge about cervical cancer and is unaware of the concept of prevention. If the women had full information on cervical cancer and its prevention and understood the importance of screening their response to NCCP will be better. Hence, extensive health education to the public is needed regarding cervical cancer. Utilization of the services of media like television, newspaper and radio can have massive impact in improving the knowledge. It is now time to reschedule the new policy regarding the new focus on this disease. New ideas and policies should be generated so that sustainable development may be ensured through effective knowledge regarding the disease in every level of community .

\section{References}

1. AP Kurkure, BB Yeole. Social inequalities in cancer with special reference to South Asian countries. Asian Pacific Journal of Cancer Prevention. 2006;7(1):36-40]

2. FX Bosch, SS de Sanjosé. Human papillomavirus and cervical cancer - burden and assessment of causality. J Natl Cancer InstMonogr. 2003;31:3-13.

3. Ferlay J, Shin HR, Bray F, et al. GLOBOCAN 2008: cancer incidence and mortality worldwide. IARC Cancer Base. No. 10 Lyon, France: IARC Press; 2010. http://globocan. iarc.fr.
4. Akhter PS, Uddin MM, Sharma SK. Patterns of malignant neoplasm - A three year study, Bangladesh Medical journal 1998;27(20):29-32.

5. Nessa A, Hussain MA, Rahman JN, et al. Screening for cervical neoplasia in Bangladesh using visual inspection with acetic acid. Int J GynaecolObstet, 2010; 111, 115-8.

6. Basu P, Nessa A, Majid M et al. Evaluation of the National Cervical Cancer Screening Programme of Bangladesh and the formulation of quality assurance guidelines. J FamPlannReprodHlth Care, 2010; 36, 131-4.

7. Sangwa-Lugoma G, Mahmud S, Nasr SH, et al. Visual inspection as a cervical cancer screening method in a primary health care setting in Africa. Int J Cancer, 119, 2006; 138995.

8. R Sultana, N Sultana, clinical profile and treatment protocol of invasive carcinoma cervix, 2012.

9. Sankaranarayanan R, Budukh AM, Rajkumar R. Effective screening programmes for cervical cancer in low- and middleincome developing countries. Bull World Health Organ. 2001;79:954-62.

10. Levinson, W.Human Papillomavirus. In :revew of medical microbiology and immunology. Levinson, W(eds). $10^{\text {th }}$ Ed. The McGraw-Hill Companies,Inc.2008;p:264-265.

11. American Cancer Society, 2009 Available at. http:// www.cancer.org/ docroot/CRI/content 242X: Do we know what causes Cervical Cancer.2009. [Accessed 04 August 2009]

12. AB Miller, J Chamberlain, NE Day, M Hakama, PC Prorok. Report on a workshop of the UICC project on evaluation of screening for cancer. International Journal of Cancer. 1990;46:761-9. [

13 J Sherris, S Wittet, A Kleine, J Sellors, S Luciani, R Sankaranarayanan. Evidence-Based, Alternative Cervical Cancer Screening Approaches in Low- Resource Settings. Article en Français. 2009;35(3) SPECIAL REPORT. [

14. WHO(Regional, Southwesr Asia).Women of South- East Asia: A health Profile. 1998

15. Bingham A, Drake JK, LaMontagne DS. Sociocultural issues in the introduction of human papillomavirus vaccine in lowresource settings. Arch PediatrAdolesc Med. 2009;163:45561

16. Nganwai P, Truadpon P, Inpa C, Sangpetngam B, Mekjarasnapa $\mathrm{M}$, et al. Knowledge, attitudes and practices vis-a-vis cervical cancer among registered nurses at the Faculty of Medicine, KhonKaen University, Thailand. Asian Pac J Cancer Prev. 2008;9:15-18.

17. Anya SE, Oshi DC, Nwosu SO, et al. Knowledge, attitude and practice of female health professionals regarding cervical cancer and Pap smear. Niger J Med. 2005;14:283-6.

18. Ali SF, Ayub S, Manzoor NF, Azim S, Afif M, et al. Knowledge and awareness about cervical cancer and its prevention amongst interns and nursing staff in tertiary care hospitals in Karachi, Pakistan. PLoS ONE. 2010;5(6):e11059. doi: 10.1371/journal.pone.0011059.

19. McCarey C, et al. Awareness of HPV and cervical cancer prevention among Cameroonian healthcare workers. BMC Women's Health. 2011;11:45

20. Mutyaba TF, Mmiro A, et al. Knowledge, attitudes and practices on cervical cancer screening among the medical workers of Mulago Hospital, Uganda. BMC Med Educ. 2006;6:13. 
21. Mwaka AD, Orach CG, Were EM, Lyratzopoulos G, Wabinga $\mathrm{H}$, Roland M: Awareness of cervical cancer risk factors and symptoms: cross-sectional community survey in post-conflict northern Uganda. Health Expect. 2015

22. Tiro JA, Meissner HI, Kobrin S, Chollette V. Cancer Epidemiol. Biomarkers Prev.2007;16(2): 288-94.

23. Twinomujuni C, Nuwaha F, Babirye JN. Understanding the Low level of cervical cancer screening in Masaka Uganda using the ASE model: a community-based survey. PLoS One. $2015 ; 10(6)$ :e0128498. doi: 10.1371/journal.pone. 0128498

24. YJia, S Li, R Yang, H Zhou, Q Xiang, T Hu. Knowledge about Cervical Cancer and Barriers of Screening Program among Women in Wufeng County, a High-Incidence Region of Cervical Cancer in China. PLoS One. 2013;8(7) e67005. Published online 2013 July 2
25. PM Lantz, ME Weigers, JS House. Education and income differentials in breast and cervical cancer screening: policy implications for rural women. Med Care. 1997;35:219-36.

26. Jia Y, Li S, Yang R, Zhou H, Xiang Q, Hu T, Zhang Q, Chen $\mathrm{Z}$, Ma D, Feng L. Knowledge about cervical cancer and barriers of screening program among women in Wufeng County, a high-incidence region of cervical cancer in China. 2013.

27. Mingo AM, Panozzo CA, DiAngi YT, Smith JS, Steenhoff AP, Ramogola-Masire D, Brewer NT. Cervical cancer awareness and screening in Botswana. Int J Gynecol Cancer. 2012;22(4):638-44..

28. AshrafunNessa, Muhammad Anwar Hussain, Mohammad Harun Ur Rashid, Nargis Akhter, Joya Shree Roy, RomenaAfroz, Role of Print and Audiovisual Media in Cervical Cancer Prevention in Bangladesh, Asian Pacific Journal of Cancer Prevention,2013:14:3131-37. 